\title{
Podem as imagens devorar os corpos?
}

\author{
Norval Baitello Júnior
}

P

título da minha fala é um pouco provocador: podem as imagens devorar os corpos? Tentarei começar pela resposta. A resposta é sim. Agora, mostrar como isso acontece é o que eu vou tentar a partir de agora.

Há alguns anos atrás eu dei um curso em uma universidade européia com o título "Podem as imagens devorar as pessoas?", e imaginei que não fosse aparecer ninguém para fazer esse curso. Era inverno, o curso era aos domingo de manhã na universidade, $50 \mathrm{~cm}$ de neve e quando eu cheguei à universidade tinham umas 100 pessoas na porta da universidade esperando a universidade ser aberta e ao final 400 pessoas se inscreveram para este curso que foi em Viena. Aquilo me deixou intrigado. Afinal, será realmente que as pessoas estão com medo das imagens ou será que elas estão procurando saber se isso vai acontecer e já pode ser percebido? E o curso deu um samba, deu um belo samba porque durou dois meses e nos dois meses o público não caiu, os 400 ficaram lá e todos eles testaram, fizeram os trabalhos de conclusão, fizeram prova e eu vou tentar resumir um pouco essa idéia que ao longo desses poucos anos foi sendo desdobrada e aperfeiçoada, a idéia de que as imagens devoram as pessoas.
Eu mudei de pessoas para corpos porque, se a gente fala em corpos, a gente enfatiza que a devoração é mesmo material, é a vida que está sendo devorada - e essa vida com tudo que a vida pressupōe, tem direito, ou seja, é nossa carne, são os nossos ossos vivos que elas podem devorar. E aí eu vou passear um pouco por esses meandros, por esses caminhos das imagens e dos corpos.

Evidente que vivemos em um mundo no qual imagens e corpos se relacionam intensamente, às vezes se misturam, às vezes se confundem e às vezes se apagam uns aos outros. Mas o que é imagem afinal? De onde vieram as imagens? De onde nasceram as imagens que nós temos hoje em qualquer lugar por aí, espalhadas pela rua, nos celulares, nos livros, nas revistas, no espaço público, no espaço privado? As máquinas de imagem, as muitas máquinas de imagem além das imagens impressas, as imagens técnicas que são imagens de luz, telas, as imagens estáticas, as imagens animadas. Nós vivemos num mundo povoado pelas imagens e pelas pessoas e, portanto, não existe porquê, não existe um senso, um licenciamento das imagens. Nós não sabemos qual é a proporção, nós só sabemos que elas são muito mais numerosas do que nós.

Norval Baitello Junior é professor de Teoria da Mídia e Teoria da Imagem da PUC-SP. 
A questão da ocupação do planeta, da população do planeta, é uma questão ecológica. Quando falamos do planeta Terra e seu destino possível, estamos trabalhando com um pensamento ecológico. Ou seja, o nosso meio ambiente está não apenas ocupado pelos corpos, pelas pessoas, mas está também ocupado pelas imagens.

A ecologia descobriu já há um bom tempo que afinal de contas nós não somos os seres mais solitários sobre o planeta. Nós tomamos o lugar do planeta para os seres humanos, mas os verdadeiros donos do planeta, que pertencem ao reino animal, são os insetos. São eles que comandam e dominam nosso planeta. Quando há uma crise no mundo dos insetos essa crise afeta diretamente a nós e é por isso que até a agricultura toma muito cuidado hoje com seus inseticidas, porque não é muito econômico matar os insetos. Matando os insetos, matam-se os peixes porque os peixes não têm comida, mata-se a agricultura porque os insetos são polinizadores e matam-se os pequenos animais que também se alimentam dos insetos, e assim por diante. Existe uma cadeia. Quando nós falamos de ecologia - eu já vou mostrar porque eu estou falando dos insetos - nós falamos sempre de um ambiente e as imagens são a população do meio ambiente cultural em que nós vivemos. Então elas ocupam o meio ambiente que nós criamos e chamamos de cultura humana.

A cultura é enormemente poderosa, porque os seres humanos criam, criaram a cultura, que é o mundo imaginário que nos cerca, e entraram nesse mundo imaginário e vivem dependendo desse mundo imaginário.

Uma outra definição de cultura poderia ser o mundo das imagens. Mundo imaginário é o mundo das imagens. Então o que faz parte da cultura, do mundo da cultura? Todas as nossas religiōes, todas as nossas crenças, todas as nossas histórias, todo o nosso imaginário, todos os nossos desejos, tudo o que afinal de contas a gente cria e conta de geração a geração. É como enxergar um saci-pererê. Eu não preciso enxergar o verdadeiro corpo de um saci-pererê, por- que ele é um ser de cultura. As histórias infantis que nós contamos para as nossas crianças, as sereias etc. Todos eles existem efetivamente como imagens. Assim como tais seres imaginários, nós podemos afirmar tranqüilamente que os deuses também existem. Todas as religiões ficariam, ficam, aliás, muito felizes porque aquela velha polêmica, Deus existe ou Deus não existe, está ultrapassada. A idéia de que Deus morreu está mais ultrapassada ainda. Deus não vai morrer nunca, porque como imagem ele está em todos os lugares, convive conosco. Isso só para dar alguns exemplos de imagens. A mesma coisa o demônio, que também é uma imagem. Se Deus existe, nós não podemos negar o direito de existência também aos demônios. E por que não falar sempre no plural, porque são muitos? Prefiro falar também no plural os deuses, que também são muitos. Cada um de nós tem os seus deuses e eles vão se multiplicando. Enfim, esse é o mundo das imagens que nós criamos.

A este mundo nós podemos dar uma porção de nomes, como nomeamos as coisas. Podemos dar um nome para um carro, podemos dar um nome para o próprio celular, para o bichinho de estimação, para o lápis, para a caneta, para o computador. Damos que nome para esse mundo das imagens? O nome mais geral e mais aceito é cultura. Então a cultura humana é o conjunto de todos os imaginários políticos, imaginários sociais, imaginários míticos, religiosos, todos os imaginários possíveis. Conjunto de imaginários significa conjunto de imagens.

A palavra imagem está sendo usada aqui para uma coisa que nem sempre pode ser vista. Foi assim que nasceram as imagens nos espaços invisíveis, ou seja, no primeiro espaço invisível: na nossa própria mente. Ali nasceram as imagens. Quando sonhamos geramos imagens, quando pensamos geramos imagens, quando estamos em qualquer situação geramos imagens. E estas são as imagens invisíveis.

As imagens invisíveis competem com as imagens visíveis no nosso mundo. As imagens internas ainda têm uma força grande no nosso mundo. Enquanto falo, gero imagens na minha 
mente. E estas imagens e a minha fala transportam imagens a cada um de vocês que, por sua vez, geram as suas próprias imagens a partir dessa fala. As imagens internas nos fizeram, afinal, seres de cultura. A capacidade de imaginar faz com que nós fujamos de uma coisa que a gente considera impossível de fugir que é fugir do tempo. Quando nós geramos imagens mentais nós saltamos no tempo, vamos para daqui a cem anos, podemos imaginar daqui a mil anos, podemos imaginar mil anos atrás, podemos imaginar hoje, podemos imaginar sem nenhum tempo e, portanto, nós fugimos da cronologia e fugimos do que existe de pior da cronologia do tempo que é o inexorável. A cada dia o espelho nos atualiza em relação a nós mesmos ou então quando olhamos uma fotografia de dez anos atrás, comparada com uma fotografia de hoje. As imagens internas não estão sujeitas a essa temporalidade, elas têm a própria temporalidade, assim como a cultura tem a própria temporalidade.

Quando o homem começou a querer pôr para fora essas imagens, primeiro ele começou a falar, contar histórias. Depois ele aprendeu técnicas com pedra, riscando pedra, depois pegou pigmentos, carvão, cores, e conseguiu, nas paredes das cavernas, reproduzir determinadas cenas. Nesse momento, as imagens começaram a sair de dentro e a ocupar o mundo externo e, é claro, elas começaram a ocupar esse mundo externo para uma função que é, até hoje, misteriosa.

Nós não sabemos para que os homens do paleolítico desenhavam cenas de bichos. Não só se desenhava, mas os animais eram desenhados com técnica maravilhosa, um realismo perfeito. Não havia aí nenhum retrato dos seres humanos, só dos animais. Então não sabemos por que. Se eles estavam ali fazendo uma homenagem, um culto, um sacrifício para melhorar a sua casa, se eles estavam fazendo uma religião para cantarem louvor à natureza, se eles estavam adorando aqueles animais como divindade, ninguém tem a menor idéia.

O máximo que eles representavam de seres humanos eram mãos. Não mãos que mo- lhavam o pigmento e se colocavam, mas mãos em negativo. Então provavelmente eles liquidificavam os pigmentos da tinta na boca, assopravam por meio de um canudinho de forma que as mãos ficavam o negativo e o contorno de pigmentos de mãos. E havia também seres humanos esquemáticos, como aquilo que costumamos fazer quando estamos com pressa: costumamos desenhar um risquinho, dois risquinhos que são as duas pernas e dois risquinhos de cima que são os dois braços e uma bola em cima que é a cabeça. O máximo que era representado dos seres humanos era isso.

Essa foi a grande passagem, a primeira, vamos dizer. A primeira passagem das imagens internas para as imagens externas. Vamos dar um salto, 40 mil anos, 50 mil anos, para os dias de hoje. Todos os espaços estão ocupados pelas imagens, desde a nossa sala de visita até nosso quarto, até o banheiro, as ruas, os banheiros públicos e os carros. Todos os lugares estão ocupados por imagens feitas pelos homens. Qual o efeito disso? O efeito é que existe uma lógica das imagens externas que querem entrar no espaço das imagens internas. Há uma guerra e todas as imagens querem ocupar o espaço das imagens internas.

A guerra é pela conquista do espaço interno e a conquista e ocupação do espaço interno podem significar o banimento, o apagamento ou a destruição das imagens originais que guardamos por tantos anos. Sobre essa guerra das imagens foram escritas coisas muito interessantes, como por exemplo, o que um pensador francês escreveu sobre a guerra das imagens na época da colonização do México. O livro se chama $A$ guerra das imagens e o autor é Sergei Gruzinski. Neste livro ele conta como os índios mexicanos, que tinham um imaginário riquíssimo, foram dominados pelos espanhóis na época da colonização. O que o autor afirma é que a principal arma dos espanhóis não eram os canhôes e nem o cavalo, porque muito se conta a respeito do cavalo, muito se conta a respeito da brutalidade dos colonizadores espanhóis e portugueses. No México, foram as imagens que 
conquistaram os índios mexicanos. E quais imagens? Que imagens existiam? Quais eram as imagens que dominavam nosso mundo? Eram as imagens religiosas.

Na pré-história, as imagens nas cavernas eram as imagens míticas. Que imagens os gregos produziam? Imagens sob a forma de escultura, imagens sob a forma de relevos, imagens em desenhos sobre pedras. Depois, na era cristã, o lugar das imagens era nas igrejas e era muito raro que as pessoas tivessem imagens na porta de suas casas. Depois, com o tempo, as imagens foram também passeando pelas casas: então as pessoas tinham sua santa de barro, ou de madeira, na sua própria casa. As pessoas mais ricas podiam ter belos santos, santuários, nas suas casas.

Antes da invenção das máquinas de imagens, as pessoas mais ricas podiam contratar um pintor para pintar as suas imagens. E era o que os reis, os príncipes e os nobres faziam. Então posavam dois, três, quatro dias para um pintor famoso pintar o seu retrato. Quando recebiam o retrato, se não gostavam, mandavam retocar. Então a gente imagina o que faziam esses reis, esses príncipes, com os coitados dos pintores, não é? Obrigavam a retratar as pessoas muito mais bonitas do que elas eram. Quando vemos um retrato de Dom João VI, que normalmente é difamado como muito feio, a gente imagina que ele deve ter sido muito mais feio do que já é nos retratos.

Quando foram inventadas as máquinas de imagens, e não se precisava mais contratar um pintor para retratar as pessoas, a imagem começou a proliferar, a se multiplicar por todos os espaços. A partir daí começaram a ter álbuns de fotografias e depois coleções de vídeos, de filmes, e assim por diante. E hoje nós vivemos num mundo cercado de imagens.

Ora, eu discorri a respeito da beleza dos príncipes e princesas. Com a fotografia não dá para a gente fazer retoques, ou melhor, depois do computador é possível fazer retoques. Mas a fotografia, nos seus primórdios, não tinha como embelezar. E mesmo o Photoshop, que faz mi- lagres, não faz tudo também. Então as pessoas começaram a querer gerar uma boa imagem: então vamos ao cirurgião plástico.

Tem uma célebre atriz de televisão que, depois de ser fotografada pela Playboy e de muito Photoshop, pegou a foto, levou para o cirurgião plástico e disse: "faça isso, não importa o que custe". Passamos a ser cobrados - cobrados é a palavra, talvez a palavra mais dura. Posso falar que não quero ser aquilo que está ali, bonito, alto, mas nós somos cobrados a ser uma imagem. Neste momento existe uma inversão perversa do ambiente cultural sobre o ambiente natural, ou seja, das imagens sobre os corpos. As pessoas que são fotografadas, retratadas e mostradas pelo mundo das imagens são sempre pessoas consideradas aquele $1 \%$ do que se convencionou chamar a beleza. Portanto, nós podemos dizer que são irreais, ideais e irreais. Quem de nós reúne todos esses predicados para ser modelo fotográfico, modelo cinematográfico ou uma atriz dentro do padrão que a publicidade exige? Talvez muito menos que $1 \%$, que ainda são transformados em imagens ideais porque o defeitinho que ainda tem se apaga, a gordurinha que ainda restou se emagrece, como uma lipoaspiração na própria imagem. E, portanto, o que aparece é ideal e irreal. $\mathrm{E}$ as imagens aparecem quase como uma obrigatoriedade.

Todos nós somos cobrados, duramente cobrados a assumir cada vez mais traços ideais. E como é muito difícil resistir, passamos a pautar nossa vida biológica pelos padrōes da imagem, passamos a querer ser aquilo que a imagem, só a imagem, pode ser. E isto não apenas no sentido visual, mas também no sentido conceitual, no sentido da carreira. Somos obrigados a nos mostrar, a ter visibilidade, e essa visibilidade é uma outra violência contra o corpo. Às vezes nós precisamos durante tempos estar com a gente mesmo, estar com os amigos, conversar com os amigos e não estar o tempo todo desfilando. Mas quem não se mostra o tempo todo não consegue os melhores empregos. Quem não mostra o melhor do que é, falante e bem apresentável e com roupas sempre 
com aquelas etiquetinhas à vista, acaba sendo passado para trás nas situações da profissão, nas situações da escola, nas situações do espaço público anônimo, ou seja, todos nós somos cobrados a apresentar qualidades de imagens. E no momento em que somos cobrados e nos obrigamos a fazer isso porque em nome da sobrevivência somos obrigados a fazer isso, nós passamos a ter uma vida dupla, a vida do corpo e a vida da imagem. E uma vida dupla em conflito: a vida do corpo pede uma coisa e a vida da imagem pede outra.

Quanto mais a vida da imagem domina a vida do corpo mais este corpo vai abrindo mão da sua própria existência. Os casos mais extremos, mais dramáticos e reais, são os casos de morte por anorexia, pois as modelos são profissionais da imagem, que têm que levar uma vida de imagem. E aí ocorrem os casos extremos da morte do corpo em nome da imagem. Mas a maior parte dos casos não são extremos, a maior parte dos casos são reais. O corpo continua sobrevivendo, mas com uma restrição do seu imaginário e, conseqüentemente, um empobrecimento do mesmo. Portanto, um empobrecimento da cultura, da capacidade de imaginação, da capacidade criativa. Um empobrecimento da capacidade de gerar imagens internas, porque o ataque das imagens externas foi tão avassalador que as pessoas passam a, ao invés de produzir as suas próprias imagens, reproduzir as imagens pré-fabricadas que são entregues diariamente a elas.

Um exemplo concreto é o que acontece na Europa, onde cresce um fenômeno que preocupa os governos, que é o fenômeno do neoanalfabetismo. No Brasil estamos acostumados com uma alta taxa de analfabetismo que, apesar de tanto esforço, não se consegue reduzir drasticamente - se reduziu substancialmente, mas não drasticamente. Na Europa, no Japão, nos Estados Unidos, porém, eles conseguiram atingir o analfabetismo zero a partir da idade escolar e estão preocupados que as pessoas saiam da escola e desaprendam a ler. Por que? Porque tudo o que elas vêem são imagens visuais, são filtros, televisão, rádio, cinema, vídeo. E não se acostumam a ler mais textos, passam a identificar as coisas apenas pelas marcas comerciais. Então conhecem Coca-cola pelo desenho da garrafa, não porque lêem o rótulo. Conhecem determinadas revistas pelo desenho, pelo tipo gráfico da revista e só folheiam.

Já existem até mesmo jornais voltados para este tipo de público de neo-analfabetos. São jornais de alta tiragem. Um desses jornais na Alemanha se chama Bild, que significa imagem, e tem uma tiragem de sete milhões de exemplares por dia. Todos os dias, sete milhões de exemplares, e o que tem nesse jornal? $\mathrm{Na}$ primeira página tem uma foto, normalmente de uma bela mulher seminua, quando não tem uma bela tragédia com mortes, sangue etc. E uma matéria de quatro linhas, uma vez que as pessoas que compram esse jornal não sabem ler mais do que quatro linhas. A partir da quinta linha já não sabem mais o que estão lendo, já não prestam mais atenção. Isso se chama neoanalfabetismo. Isto é a conquista da mente. Uma pessoa que não lê significa que já não tem mais capacidade de processar as próprias imagens, só recebe as imagens prontas e considera que aquelas são as imagens. Significa que uma pessoa que lê um jornal como esse tem como assunto para conversar com seus amigos aquilo que está lá nas manchetes do jornal. Significa uma restrição de imaginário. Isso foi o que chamei de problema ecológico, um problema ecológico que vai afetar a qualidade de vida das pessoas. E é claro, todos continuamos vivos, mesmo falando de futebol, falando de moda, falando do tempo.

Nós não estamos fora do mundo, mas nós temos que ocupar conscientemente o nosso espaço neste mundo e não deixar que o mundo ocupe todo o nosso espaço interior. A isso eu chamo de devoração pelas imagens e eu criei, ou melhor, montei uma palavra para dar nome a esse fenômeno, que é a palavra iconofagia. Um ícone é uma imagem e, portanto, fagia é devoração. Então quando existe um processo de devoração das imagens como é capturado? 
Em primeiro lugar o corpo produz as imagens. Segunda etapa, o corpo consome as imagens. Terceira etapa, se alimenta de imagens. Quem não adora ver um lindo filme? Quem não adora ver uma linda foto? Quem não adora ver uma bela telenovela? Também isso existe, não é? Quem não adora ver, enfim, um belo quadro? Quem não adora ver uma bela roupa? Quem não adora ver uma bela mulher? Um belo homem? Nós consumimos imagens, é absolutamente legal, não é proibido, não faz mal à saúde. Pelo contrário, faz bem à saúde ver coisas bonitas, ver coisas boas, curtir. Quem não adora? Eu estou falando de imagem, mas pode ser imagem acústica. Quem não adora ouvir uma bela música ou ver um belo show? Portanto, faz parte da nossa vida alimentar nosso imaginário com imagens que geram as nossas outras imagens.

Então as nossas imagens geram novas imagens a partir das nossas imagens interiores: essa é uma etapa. A etapa próxima é quando se desenvolve um tipo de gula pelas imagens. As imagens são tantas que elas começam a competir pelo nosso olhar. Então já não basta mais um cartaz, é preciso um outdoor, já não basta mais um outdoor é preciso um painel, já não basta mais um painel é preciso um painel eletrônico móvel etc. Elas começam a competir pelo nosso olhar. Duas coisas podem acontecer: ou o nosso olhar se cansa e começa a não enxergar mais ou então o nosso olhar engole todas essas imagens e as armazena ocupando todo o espaço das nossas próprias imagens e, portanto, nós devoramos as imagens quando entramos nessa etapa.

A etapa seguinte é que não conseguimos fechar a nossa capacidade de receber imagens e, portanto, queremos nos transformar em imagens. Elas começam a nos transformar em imagens, elas é que nos devoram. A isso dei o nome de iconofagia, que é a devoração pelas imagens.

Vale a pena contar uma curiosidade antes de terminar. A palavra imagem em português, image em francês, imagen em espanhol, vem do latim e no latim a palavra é imago. E o que significava imago para os povos que falavam latim? Significava a máscara de cera ou de gesso, fabricada a partir do rosto de uma pessoa morta e, portanto, significava o retrato de um morto. Em grego era a mesma coisa, a palavra é eidolon e significa a mesma coisa que em latim. É o retrato de um morto. Os familiares de uma pessoa rica, quando esta morria, mandavam fabricar uma imago, ou, na Grécia, eidolon. E guardavam aquilo como única recordação do morto, pois não havia fotografia, não tinha como pintar a pessoa. Então eles fabricavam e era a última recordação do morto.

A imagem visual tem uma força enorme de captura do nosso olhar e é porque, talvez, na nossa memória profunda, nós recordemos este medo da morte e por medo da morte nós fabricamos imagens e por medo das imagens nós fabricamos mais imagens e as imagens nos capturam lá no canto. Talvez elas nos ameacem e elas nos recordem muito profundamente que todos somos mortais e, para fugir da morte, existe uma saída: antecipar a própria morte. E essa é a saída que oferece o mundo das imagens que nos devoram, das imagens insistentemente proliferadoras e proliferadas por este mundo afora e que competem pelo nosso olhar. 